\title{
CGS System
}

National Cancer Institute

\section{Source}

National Cancer Institute. CGS System. NCI Thesaurus. Code C42564.

CGS system is a clustering of metric units based on the centimeter, the gram, and the second. The ratio between a CGS unit and the corresponding MKS unit is usually a power of 10. The CGS system was introduced formally by the British Association for the Advancement of Science in 1874. Although some of the CGS units remain in use (e.g. by scientists working in small subject contexts) for a variety of purposes, they are being replaced gradually by the SI units selected from the MKS system. 